\title{
Les pérégrinations de Saint-Philibert. Genèse d'un réseau monastique dans la société carolingienne
}

Presses universitaires de Rennes, 2009, 458 p.

\section{Isabelle Cartron}

\section{(2) OpenEdition}

\section{Journals}

Édition électronique

URL : https://journals.openedition.org/cem/11632

DOI : $10.4000 /$ cem. 11632

ISSN : 1954-3093

Éditeur

Centre d'études médiévales Saint-Germain d'Auxerre

Référence électronique

Isabelle Cartron, «Les pérégrinations de Saint-Philibert. Genèse d'un réseau monastique dans la société carolingienne ", Bulletin du centre d'études médiévales d'Auxerre / BUCEMA [En ligne], 14 | 2010, mis en ligne le 14 octobre 2010, consulté le 22 septembre 2022. URL : http://journals.openedition.org/ cem/11632 ; DOI : https://doi.org/10.4000/cem.11632

Ce document a été généré automatiquement le 22 septembre 2022.

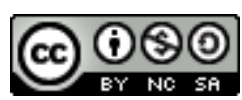

Creative Commons - Attribution - Pas d'Utilisation Commerciale - Partage dans les Mêmes Conditions 4.0 International - CC BY-NC-SA 4.0

https://creativecommons.org/licenses/by-nc-sa/4.0/ 


\section{Les pérégrinations de Saint- Philibert. Genèse d'un réseau monastique dans la société carolingienne}

Presses universitaires de Rennes, 2009, 458 p.

Isabelle Cartron

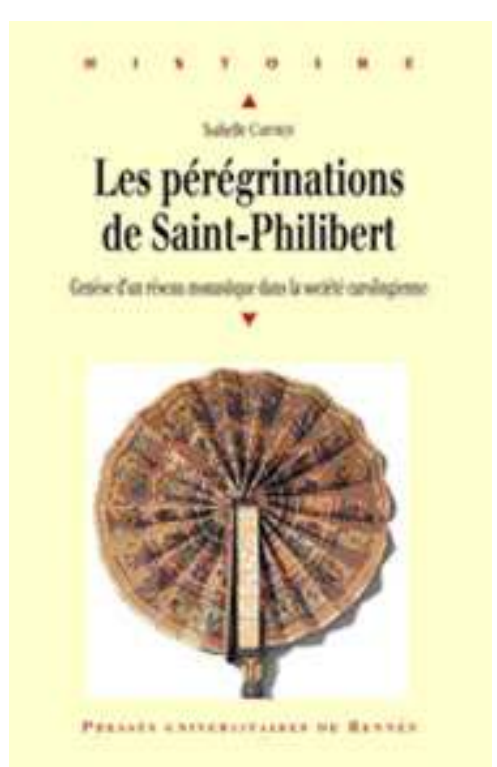

1 Les pérégrinations des moines de Saint-Philibert depuis Noirmoutier jusqu'à Tournus, en Bourgogne, sont souvent citées en exemple pour caractériser l'exode devant les incursions normandes au $\mathrm{Ix}^{\mathrm{e}}$ siècle. La confrontation avec les itinéraires des autres groupes monastiques témoigne cependant de l'originalité de cette congrégation qui ne rejoint pas son établissement d'origine. L'historiographie récente conserve d'ailleurs la marque de cette particularité dans le sens où une histoire de l'ensemble du réseau monastique, tel qu'il se constitue entre le $\mathrm{IX}^{\mathrm{e}}$ et le $\mathrm{XII}^{\mathrm{e}}$ siècle, n'a jamais été écrite. 
Pourtant, comprendre la carte générale du réseau de dépendances, telle qu'elle apparaît au début du XII ${ }^{\mathrm{e}}$ siècle, ne peut se faire sans revenir sur ces pérégrinations peu ordinaires, dont la mémoire fait partie intégrante de celle de la communauté; la période carolingienne apparait donc comme fondatrice.

D'un point de vue spatial, le domaine monastique, essentiellement regroupé dans les régions situées au sud de la Loire, privilégie les installations dans les grandes vallées fluviales : la Loire, depuis sa source jusqu'à l'estuaire; l'Allier; la Saône et le Rhône. Cette étude n'est pas uniquement fondée sur un examen des textes anciens; dans une optique interdisciplinaire, elle prend en compte l'ensemble des sources historiques à la disposition du chercheur: images, vestiges archéologiques et architecturaux. Chaque document offre ainsi un regard différent sur un même objet de recherche, à savoir la connaissance et la compréhension de la genèse de ce réseau monastique. Le lecteur ne trouvera pas ici un ouvrage d'histoire religieuse mais bien d'histoire sociale: la communauté monastique est perçue comme un acteur à part entière de la société et non comme un groupe indépendant et isolé du monde extérieur. Ce point de vue exige donc de prendre en compte les différentes politiques monastiques et les relations qui ont pu se tisser entre les moines et les élites carolingiennes afin de mieux comprendre l'implantation du réseau. À un autre niveau, il s'agit aussi de réfléchir sur l'organisation intrinsèque de la communauté.

3 Cet ouvrage est divisé en cinq parties successives reprenant le cheminement des moines, à la fois dans l'espace et dans le temps :

4 - la première partie s'articule autour du parcours des moines depuis le monastère d'Herio (Noirmoutier) jusqu'à Messais en Poitou. L'importance accordée par les moines aux désordres occasionnés par les incursions normandes montre que leur histoire s'inscrit dans une dynamique générale, mais les moines, parce qu'ils sont impliqués dans le processus de la réforme monastique, sont particulièrement soutenus pendant cette période critique ;

5 - la partie suivante pose la question d'une étape intermédiaire des moines en Auvergne en examinant le dossier épineux des actes diplomatiques à la lumière d'un contexte politique fluctuant ;

6 - la troisième s'ouvre sur l'arrivée des moines à Tournus et invite à mieux cerner les enjeux de ce voyage qui met un terme à leurs pérégrinations ;

7 - dès le dernier tiers $\mathrm{du} \mathrm{IX}^{\mathrm{e}}$ siècle, les moines acquièrent de nouveaux domaines dans les régions situées au sud du monastère (quatrième partie). Elle s'inscrit dans le contexte particulier des ambitions du comte puis roi Boson, proche de l'abbé du monastère, Geilon. Dans cette perspective, nous tentons de mieux cerner la politique menée par l'établissement dans ces régions et d'en définir les limites;

8 - la dernière partie est consacrée à l'histoire du monastère aux $\mathrm{x}^{\mathrm{e}}$ et $\mathrm{XI}^{\mathrm{e}}$ siècles. Le choix de traiter ces deux siècles d'histoire monastique d'une manière aussi synthétique résulte d'abord du médiocre état de conservation des sources pour cette période et découle également du constat d'un certain conservatisme du monastère, attaché à son passé carolingien. Trois thèmes ont été privilégiés pour aborder cette question, en écho à ceux qui ont été développés précédemment. Le premier concerne les relations du monastère avec les représentants du pouvoir dans la société - le roi, le pape et les élites -, ce qui permet d'envisager l'évolution du statut de l'établissement entre le $\mathrm{IX}^{\mathrm{e}}$ et le $\mathrm{XI}^{\mathrm{e}}$ siècle. Le culte des saints et des reliques paraît ensuite fondamental pour mesurer le 
rayonnement du monastère et mieux définir ce qui constitue son identité propre. Il préside sans doute à l'élaboration du programme monumental de reconstruction du monastère de Tournus au cours du XI ${ }^{\mathrm{e}}$ siècle. Celui-ci s'impose comme pôle principal du réseau monastique qui se structure progressivement.

INDEX

Mots-clés : réseau monastique, Philibert (saint), carolingien

Index géographique : France/Noirmoutier, France/Tournus 